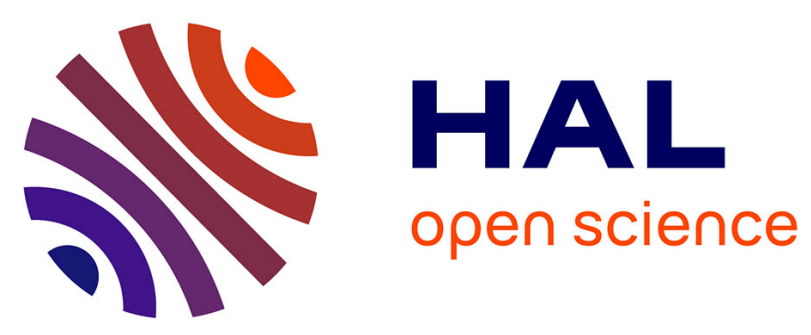

\title{
Measurement of protonic resistance of catalyst layers as a tool for degradation monitoring
}

Thomas Gaumont, G. Maranzana, Olivier Lottin, Jérôme Dillet, Sophie Didierjean, J Pauchet, L Guétaz

\section{- To cite this version:}

Thomas Gaumont, G. Maranzana, Olivier Lottin, Jérôme Dillet, Sophie Didierjean, et al.. Measurement of protonic resistance of catalyst layers as a tool for degradation monitoring. International Journal of Hydrogen Energy, 2017, 42 (3), pp.1800-1812. 10.1016/j.ijhydene.2016.10.035 . hal-01744069

\section{HAL Id: hal-01744069 \\ https://hal.science/hal-01744069}

Submitted on 27 Mar 2018

HAL is a multi-disciplinary open access archive for the deposit and dissemination of scientific research documents, whether they are published or not. The documents may come from teaching and research institutions in France or abroad, or from public or private research centers.
L'archive ouverte pluridisciplinaire HAL, est destinée au dépôt et à la diffusion de documents scientifiques de niveau recherche, publiés ou non, émanant des établissements d'enseignement et de recherche français ou étrangers, des laboratoires publics ou privés. 


\title{
MEASUREMENT OF PROTONIC RESISTANCE OF CATALYST LAYERS AS A TOOL FOR DEGRADATION MONITORING
}

\author{
T. Gaumont ${ }^{\text {a, b, c }}$, G. Maranzana ${ }^{\text {a, b }}$, O. Lottin ${ }^{\text {a, b }}$, J. Dillet ${ }^{\text {a, b }}$, S. Didierjean ${ }^{\text {a, b }}$, \\ J. Pauchet ${ }^{\mathrm{c}}$, L. Guétaz ${ }^{\mathrm{c}}$ \\ a) LEMTA, Université de Lorraine, 2 av. de la Forêt de Haye 54518 Vandoeuvre-lès-Nancy (France) \\ b) LEMTA, CNRS, 2 av. de la Forêt de Haye 54518 Vandoeuvre-lès-Nancy (France) \\ c) CEA, 17 avenue des Martyrs, 38000 Grenoble (France)
}

\begin{abstract}
The ionic resistance of a PEM fuel cell catalyst layer, as well as the double layer capacity and the high frequency resistance are estimated from the impedance spectra of $\mathrm{H}_{2} / \mathrm{N}_{2}$ operated cell, thanks to a volumetric electrode model. The impedance spectra are calculated in the case of a homogeneous distribution of resistivity and capacity, and considering both trough plane and in plane heterogeneities.

Then, results of the degradation of a MEA submitted to four different accelerated stress tests are presented. They consist of (i) a constant current operation, (ii) $1.2 \mathrm{~V}$ potential hold with nitrogen and hydrogen (iii) open circuit voltage (OCV) hold with air and hydrogen, and (iv) a start-up protocol where heterogeneous degradations are observed using a linear segmented fuel cell. This technique can provide useful information about the evolution of catalyst layer microstrucure during AST.
\end{abstract}

Key words- Electrochemical Impedance Spectroscopy, catalyst layer ionic resistance, protonic resistance, PEMFC electrode degradation, ionomer degradation, carbon corrosion

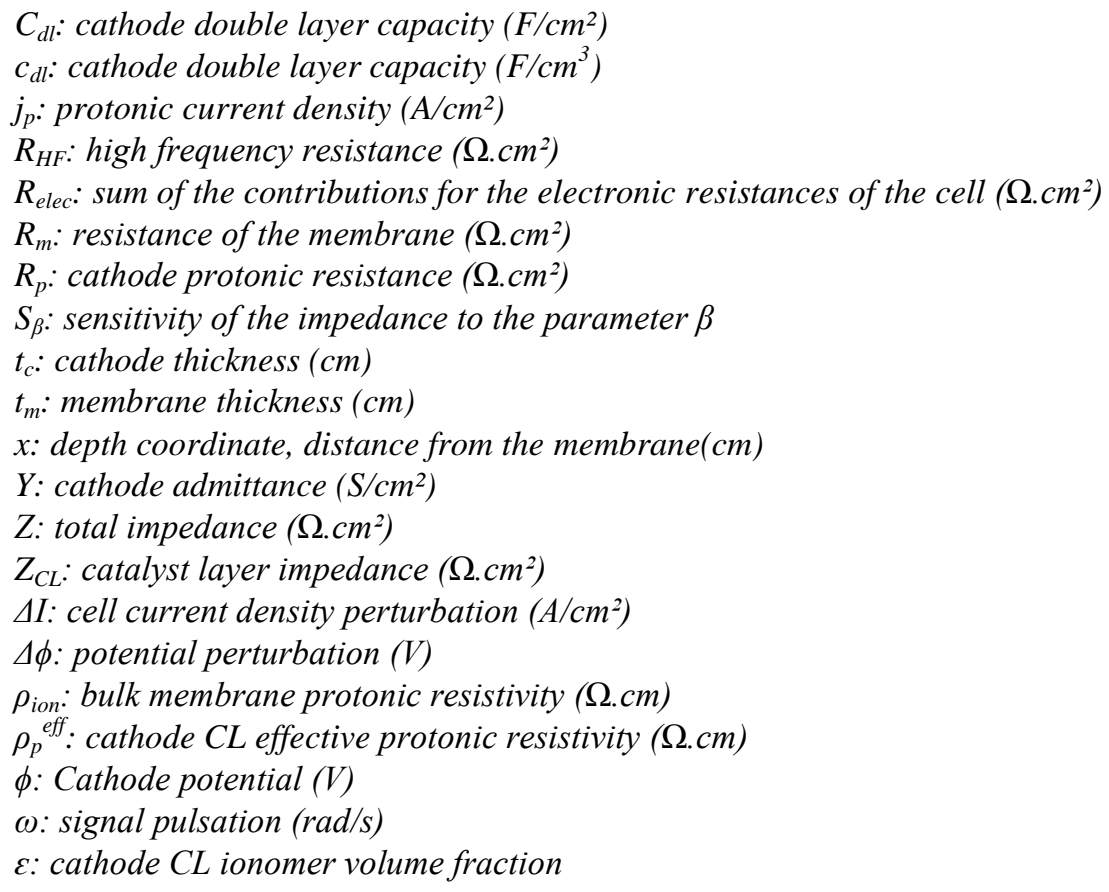

\section{$\underline{\text { Nomenclature }}$}

\section{INTRODUCTION}

Early PEMFC cathode catalytic layers were made of platinum black, consisting in Pt particles only. High Pt loadings of the cathode were required to limit the main voltage loss which was due to the oxygen reduction 
reaction (ORR). Lately, the apparition of carbon supported platinum replaced platinum black. This transformed the surface problem into a volume problem. To ensure a homogeneous ORR within the electrode, both protons and oxygen have to be carried from and to the reaction site efficiently. That for, a thin film of ionomer covers the $\mathrm{Pt} / \mathrm{C}$ catalyst, and acts (i) as an ionic pathway for the ORR and (ii) as a mechanical binder for the catalytic layer. Measuring the ionic resistance of a cathode catalyst layer (CCL) is of prime importance for the optimization of the membrane electrode assembly (MEA) structure, as well as for a better identification of the voltage losses in a PEMFC, to understand the influence of working conditions of the fuel cell, and finally to feed numerical fuel cell models.

When measuring in operando, one must be able to decorelate the various contributions leading to a voltage drop within the catalytic layer, namely: ohmic drop within the membrane, ohmic drop within the electrode, mass transport resistances and charge transfer resistances. On top of that, the membrane and electrode relative humidity varies with the current density because of water and heat production. All these contributions are thus deeply coupled. Some authors have nonetheless proposed polarization curves analysis techniques to deduce the ionic resistance induced loss from the other losses, based on a performance model [1][2]. However, humidity varies locally as a function of the current produced, as well as along the flow of gases, so that in addition of being strongly dependent on the operating conditions, neither the membrane nor the cathode ionic resistances can be considered as uniform. Moreover, the polarization curve under oxygen cathode supply is mostly sensitive to the kintetics parameters. They have to be measured very accurately to estimate precisely the ionic resistance of the catalytic layer. For these reasons, stationary in operando methods fail probably to provide accurate information concerning the ionic resistance.

Some authors also proposed ex-situ stationary methods to measure the ionic resistance of catalytic layer. In [3], [4] the authors used a $\mathrm{H}_{2}$ pump technique to measure the resistance of their samples, consisting of a pseudo catalyst layer sandwiched between two membranes. Siroma and co-workers [5] used a specific setup to measure the in-plane DC ionic resistance of a catalyst layer (CL). Their method ensured that no faradaic current was transferred from one phase to the other.

Electrochemical impedance spectroscopy (EIS) has proved to be a relevant tool to study fuel cell and in particular catalyst layers. The additional information contained at different frequencies enables to decorelate the various parameters. To the best of our knowledge, Springer et al. [6] were the first to propose an AC impedance analytical model taking into account proton transport within the electrode. Their numerical model included proton transport, oxygen transport, and the potential dependant kinetics of the ORR. Later Eikerling and Kornyshev [7] used a similar model and calculated the impedance analytically for low currents in the absence of oxygen supply limitation. Makharia et al. [8] proposed a transmission line model neglecting oxygen transport limitations and showed that the transmission line model and the physical model of Eikerling and Kornyshev were equivalent for low currents, when the charge transfer resistance can be considered as constant along the electrode. This model was used to fit experimental spectra acquired with oxygen cathode supply. They were able to estimate the protonic resistance at different currents. Kulikovsky built an analytical model of impedance [9]. This model was then used in [10] to fit experimental spectra, and to estimate the ionic conductivity of the CCL and the oxygen effective diffusivity within the CCL. More recently, Kulikovsky and Eikerling used this impedance model to measure the double layer capacity, the CCL ionic conductivity and the Tafel slope using analytical expressions [11]. These impedance methods, for small currents and in absence of oxygen transport limitations, solve some of the issues raised by stationary methods. However, the issue of the unknown local relative humidity remains, and the model includes 4 parameters.

Another approach consists in measuring the CCL ionic resistance in controlled conditions by simplifying the model. When the cell is not delivering any faradaic current, it behaves as a super capacitor, and the impedance 
response becomes much simpler. Experimentally the electrode is blocked by flushing the cathode with nitrogen or other inert gases. This method based on potentiostatic EIS was already investigated in the literature, including for super capacitors [12]-[16].

This work focused on such $\mathrm{H}_{2} / \mathrm{N}_{2}$ methods because they are simple to implement on a fuel cell bench and because the relative humidity is well controlled as a function of time, as well as over the whole cell area.

Four accelerated stress tests were performed:

- A constant current protocol was applied to ensure that no major degradation occurs in the absence of harsh (operating) conditions.

- A potentiostatic hold regime at $1.2 \mathrm{~V}_{\mathrm{vs}} \mathrm{H} 2$ was imposed to the cell as a classical carbon corrosion test, as recommended by the US Department of Energy (DOE) [17].

- An OCV protocol was performed because it is known that PFSA are chemically attacked in such conditions [17].

- And finally, a start-up (SU) protocol was performed.

During these AST, measuring $\mathrm{H}_{2} / \mathrm{N}_{2}$ EIS parameters not only provides information about the ability of the electrode and the membrane to carry protons, but also about the entire microstructure of the electrode, as discussed in the experimental section.

\section{PROTONIC RESISTANCE MEASUREMENT}

\subsection{D homogeneous model}

In this model, the carbon phase was considered equipotential because of the 100 to 1000 times higher conductivity of carbon than the ionic phase [5]. All faradaic reactions were neglected, including carbon oxidation and hydrogen crossover. The distributions of resistivity $\left(\rho_{p}\right)$ and capacity $\left(c_{d l}\right)$ were considered as homogeneous in both trough-plane and in-plane directions.

In this macro homogeneous electrode model, a pore is considered as an assembly of carbon particles covered with ionomer. All pores have the same volume and the same values of effective protonic resistivity $\rho_{p}$ and volume double layer capacitance $c_{\mathrm{d} d}$. In absence of faradaic current, the charge conservation equation (Eq. 1) and Ohm's law (Eq. 2) write as follows:

$$
\begin{array}{cc}
c_{d l} \frac{\partial \phi}{\partial t}+\frac{\partial j_{p}}{\partial x}=0 & \text { Eq. } 1 \\
\frac{\partial \phi}{\partial x}=-\rho_{p} j_{p} & \text { Eq. } 2
\end{array}
$$

With $j_{p}$ the protonic current density and $\phi$ the electrolyte potential.

One can derive the following expression for the impedance of the CL, as used in [18], or adapted from [8] for an infinite charge transfer resistance:

$Z_{C L}=\frac{\Delta \phi}{\Delta I}=\sqrt{\frac{R_{p}}{i C_{d l} \omega}} \operatorname{coth}\left(\sqrt{i R_{p} C_{d l} \omega}\right)$

With $R_{p}=\rho_{p} t_{c}\left(\right.$ in $\left.\Omega . \mathrm{cm}^{2}\right)$, and $C_{d l}=c_{d l} t_{c}\left(\right.$ in $\mathrm{F} / \mathrm{cm}^{2}$ ), the surface protonic resistance and double layer capacitance respectively, $\mathrm{t}_{\mathrm{c}}$ being the thickness of the CCL. 
In the high frequency domain, considering that $\operatorname{coth}(x) \rightarrow 1$ when $x \rightarrow \infty$, it yields:

$$
Z_{C L}(\omega \rightarrow \infty) \approx \sqrt{\frac{R_{p}}{i C_{d l} \omega}}
$$

Eq. 4

In the low frequency domain, considering that $\operatorname{coth}(x) \approx \frac{1}{x}$ when $\mathrm{x} \rightarrow 0$,

$$
Z_{C L}(\omega \rightarrow 0) \approx \frac{1}{i C_{d l} \omega}
$$

Eq. 5

- At very high frequencies the electrode impedance is null. Physically, only the pores close to the membrane are active, the rest of the electrode is shunt by the double layer capacitances. In this case, only the carbon carries the current, i.e. the current is carried by the electronic branch of the transmission line represented in Figure 1.

- When decreasing the frequency, the impedance can be approximated as in Eq. 4. It has a diffusive behavior with a linear $45^{\circ}$ branch in the Nyquist plot. The current is transported both by the ionomer close to the membrane and by the carbon phase close to the GDL. The double layer capacities of the pores further from the membrane have enough time to charge. The total ionic resistance of the active electrode increases and the pores located deeper contribute to the ionic current, until reaching the CL/GDL interface.

- At this point, when $\omega<<1 / \mathrm{R}_{\mathrm{p}} \mathrm{C}_{\mathrm{dl}}$, the whole of the CL contribute to the ionic current and the electrode behaves as a pure capacity (Eq. 5). Decreasing $\omega$ only leads to charge more slowly the capacities.

When considering the whole fuel cell, one can neglect the anode because of the fast HOR reaction and because there is no limitation or artifact linked with $\mathrm{H}_{2}$ mass transport. This assumption is discussed in [8] [18] [19] [20]. The global impedance is the sum of the CCL impedance, the membrane resistance $\mathrm{R}_{\mathrm{m}}$ and the other electronic resistance attributed to the acquisition system, the GDL, the bipolar plates and the contact resistances, $\mathrm{R}_{\text {elec: }}$ :

$$
Z(\omega)=R_{m}+R_{\text {elec }}+Z_{C L}
$$

In the experimental section, the spectra are fitted using the following expression, considering $R_{H F}=R_{m}+R_{\text {elec }}$ $Z(\omega)=\sqrt{\frac{R_{p}}{i C_{d l} \omega}} \operatorname{coth}\left(\sqrt{i R_{p} C_{d l} \omega}\right)+R_{H F} \quad$ Eq. 7

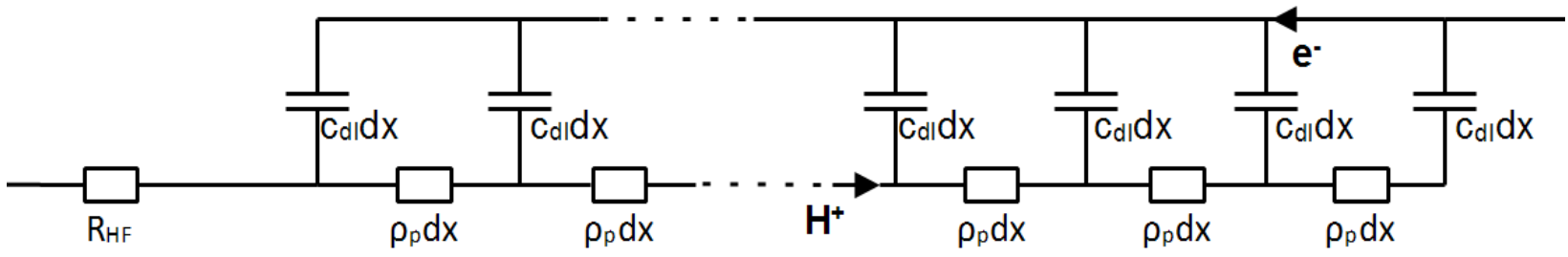

Figure 1: Equivalent transmission line of the cathode $\mathrm{H}_{2} / \mathrm{N}_{2}$ impedance. Membrane interface is on the left, GDL interface is on the right. 
This analytical model is equivalent to the transmission line depicted in Figure 1 with an infinite number of RC loops, provided $\rho_{p}$ and $c_{d l}$ are kept constant. In practice, the impedance of the transmission line can be computed iteratively considering the following sequence:

$$
\begin{aligned}
& Z_{0}=\rho_{p, 0} d x+\frac{1}{i c_{d l} \omega} d x \\
& Z_{n}=\left(\frac{1}{Z_{n-1}}+\frac{1}{i c_{d l, \mathrm{n}} \omega} d x\right)^{-1}+\rho_{p, n} d x
\end{aligned}
$$

\section{2. $1 D$ heterogeneous model}

The transmission line enables to easily compute the impedance of electrodes with a heterogeneous distribution of resistivity or double layer capacitance.

When computing impedances with heterogeneous distributions of resistivity and/or double layer capacitance, important differences occur depending on the shape of the profile. A similar work was carried out in the case of $\mathrm{H}_{2} / \mathrm{O}_{2}$ spectra by Gerteisen in [21]. The author underlines that such in-depth heterogeneities may appear during the MEA manufacturing process. In the case of catalyst coated membranes (CCM) for instance, if the ionomer and the solvent of the catalyst ink are not perfectly miscible, a positive gradient or a negative gradient (respectively blue profile or red profile of Figure 2) may be obtained, or for catalyst coated backing (CCB), if the catalyst layer penetrates the membrane during hot pressing, the red profile of Figure 2 may be obtained. For a higher $\rho_{p}$ close to the GDL, the resistance $R_{p}$ estimated with the homogeneous model will be overestimated. On the contrary, for a lower resistivity close to the GDL, the resistance $R_{p}$ estimated with the homogeneous model will be underestimated (see Figure 2).

The same simulation as that of Figure 2 was carried out considering double layer capacity heterogeneous distribution. For a higher volumetric double layer capacitance close to the GDL, $R_{p}$ will be overestimated, and for a lower volumetric double layer capacitance close to the GDL $R_{p}$ will be underestimated. These results show that a degradation of the cathode ionomer affecting preferentially one interface will be difficult to interpret when fitting with the homogeneous model. More specifically, a chemical attack of the ionomer close to the GDL will lead to a lower estimated $R_{p}$, provided the ionomer close to the membrane remains stable. 

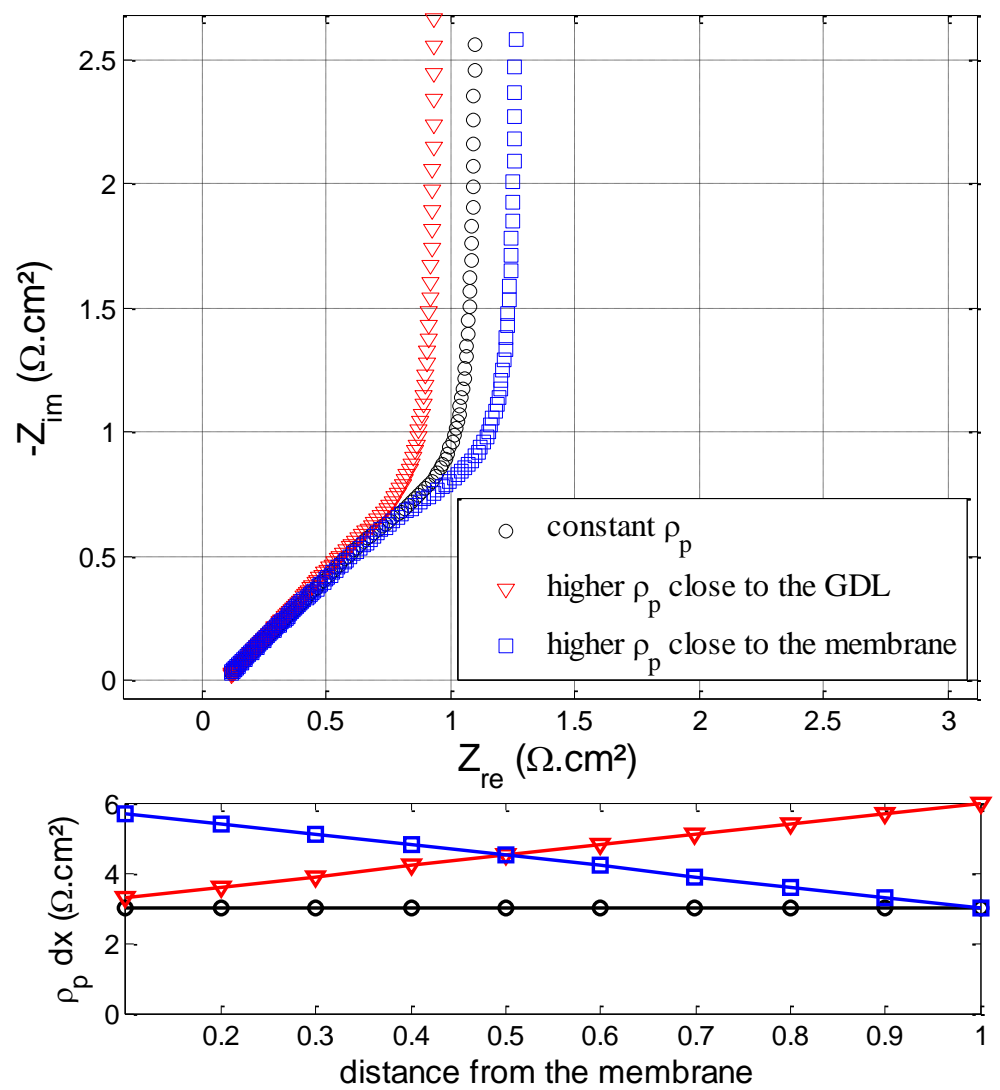

Figure 2: EIS spectra simulated with the transmission line model represented in Figure 1 with various resistivity profiles.

\subsection{Pseudo 2D model with in plane heterogeneities}

In plane heterogeneities may occur for different reasons such as MEA non-ideal manufacturing process (see Figure 3), or heterogeneous degradations at the rib/channel scale. The simulation of an electrode with a heterogeneous thickness $t_{c}$ was performed by considering a parallel arrangement of $n$ transmission lines of different thicknesses (see Figure 4 and Eq. 10 and Eq. 11). This simulation was done:

- for a homogenous thickness profile (black circles),

- for a sinusoidal thicknesses profile (blue triangles),

- for a square thicknesses profile (green squares).

The mean thickness used for each profile equals $3 \Omega . \mathrm{cm}^{2}$ and the number of transmission lines in parallel was $\mathrm{n}=100$. This model neglects the in-plane diffusion of potential, which means that it can be considered as valid only for a large planar period $\mathrm{L}\left(\right.$ i.e $\left.L>>t_{c}\right)$.

$Z_{\text {tot }}=\frac{1}{Y_{t o t}}$

Eq. 10

with

$Y_{\text {tot }}=\frac{1}{n} \sum_{i=1}^{n} \frac{1}{Z_{i}}$

Eq. 11 


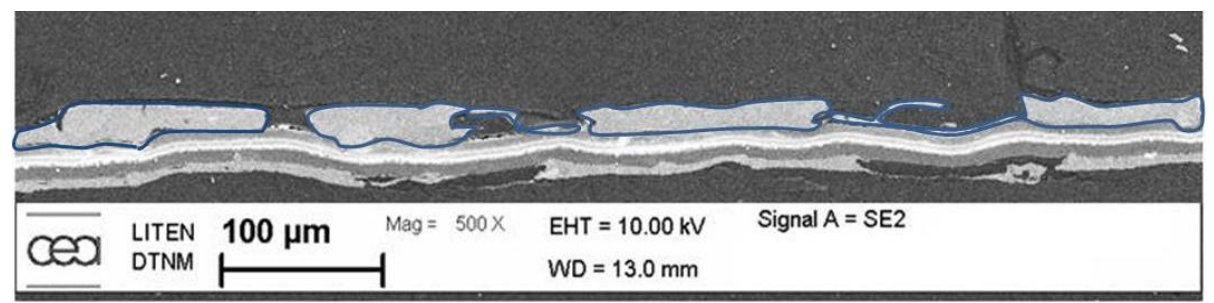

Figure 3: MEB picture a heterogeneous fresh MEA

The part highlighted in blue is the cathode catalyst layer.

A result of this simulation is that a heterogeneous distribution of the thickness may lead to overestimate the mean $R_{p}$. Another result is that in the case of a sinusoidal profile, the thickness varies continuously, with an infinite number of cutoff frequencies. This explains the continuous growth of the slope from $45^{\circ}$ to $90^{\circ}$ in the Nyquist plot, instead of a single discontinuity in the homogeneous case. In this case, using a homogeneous model to fit $\mathrm{H}_{2} / \mathrm{N}_{2}$ spectra measured on a heterogeneous catalyst layer cannot give satisfactory results. A regular shape of $\mathrm{H}_{2} / \mathrm{N}_{2}$ spectra, with a clearly defined $45^{\circ}$ slope proves a homogeneous thickness of the catalyst layer. The same model can be used to simulate heterogeneous dispersion of the ionomer within the CL, by using a constant thickness but heterogeneous in-plane distribution of $\rho_{p}$ or $c_{d l}$. In any case, such heterogeneities will lead to irregular spectra and make the fitting process complicated using the homogeneous model.

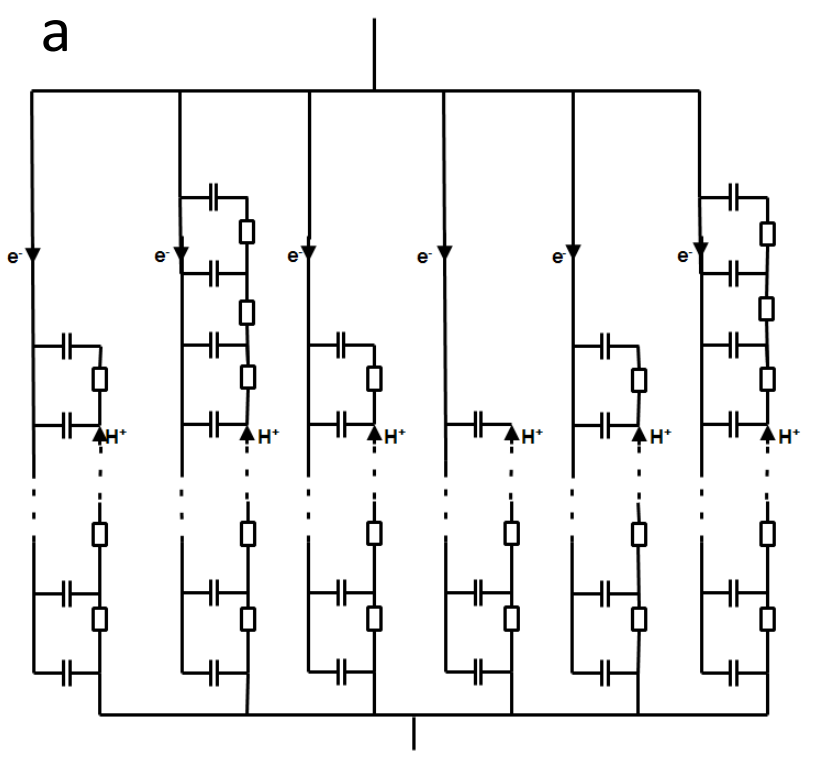

b
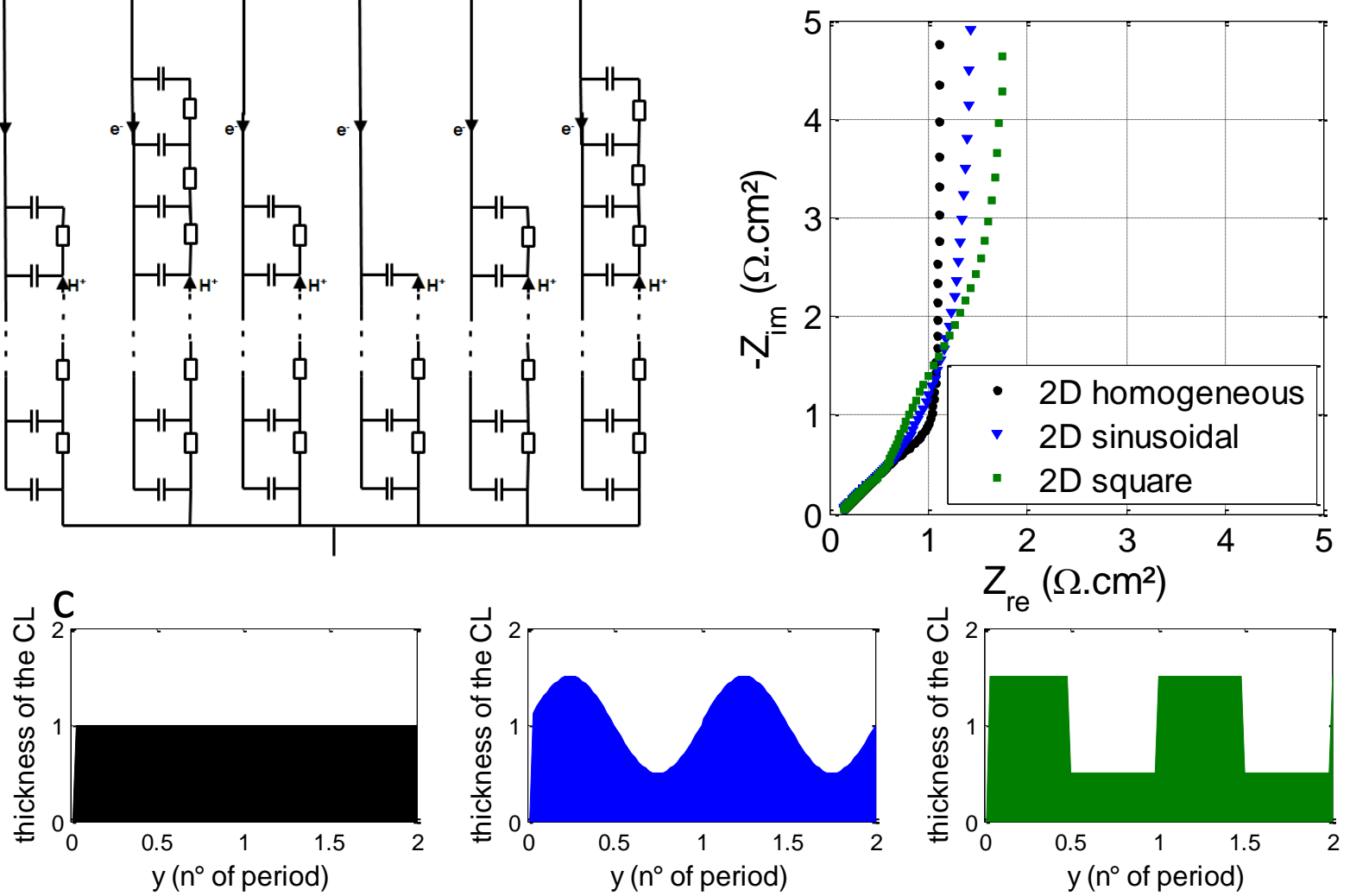

Figure 4: An example of equivalent electrical circuit that can be used for the simulation (a), EIS spectra simulated (b) for heterogeneous distribution of the CL thickness with different profiles represented below (c). 


\subsection{Estimation of the parameters and frequency sensitivity of the system}

EIS models aim at estimating parameters from experimental impedance spectra. When estimating parameters from EIS spectra, particularly for a high number of them, one has to ensure that they are not correlated and that the model is sensitive enough to each of them. This can be done using the sensitivity matrix.

The sensitivity coefficient $S_{\beta}$ to each parameter $\beta$ of the model ( $\beta$ being $R_{p}, C_{d l}$, or $R_{H F}$ ) can be defined as:

$$
S_{\beta}=\frac{\beta}{|Z|} \frac{\partial|Z|}{\partial \beta}
$$

Eq. 12

$S_{6}$ is a dimensionless reduced coefficient that is used to compare the sensitivities of the different parameters. A problem is said ill-conditioned when there are correlations between parameters, which means that the sensitivities are multi-collinear. In this case, the sensitivity matrix is non-invertible: there are several sets of parameters minimizing the least mean square. Usually, for a model with 2 parameters, one can check if the 2 parameters are correlated simply by plotting the sensitivities versus the explanatory variable (the frequency in our case), and check whether they are proportional. However for 3 parameters or more, the condition number must be computed to give an idea of the degree of correlation between them. For an ideally well-conditioned problem, the condition number equals 1 .
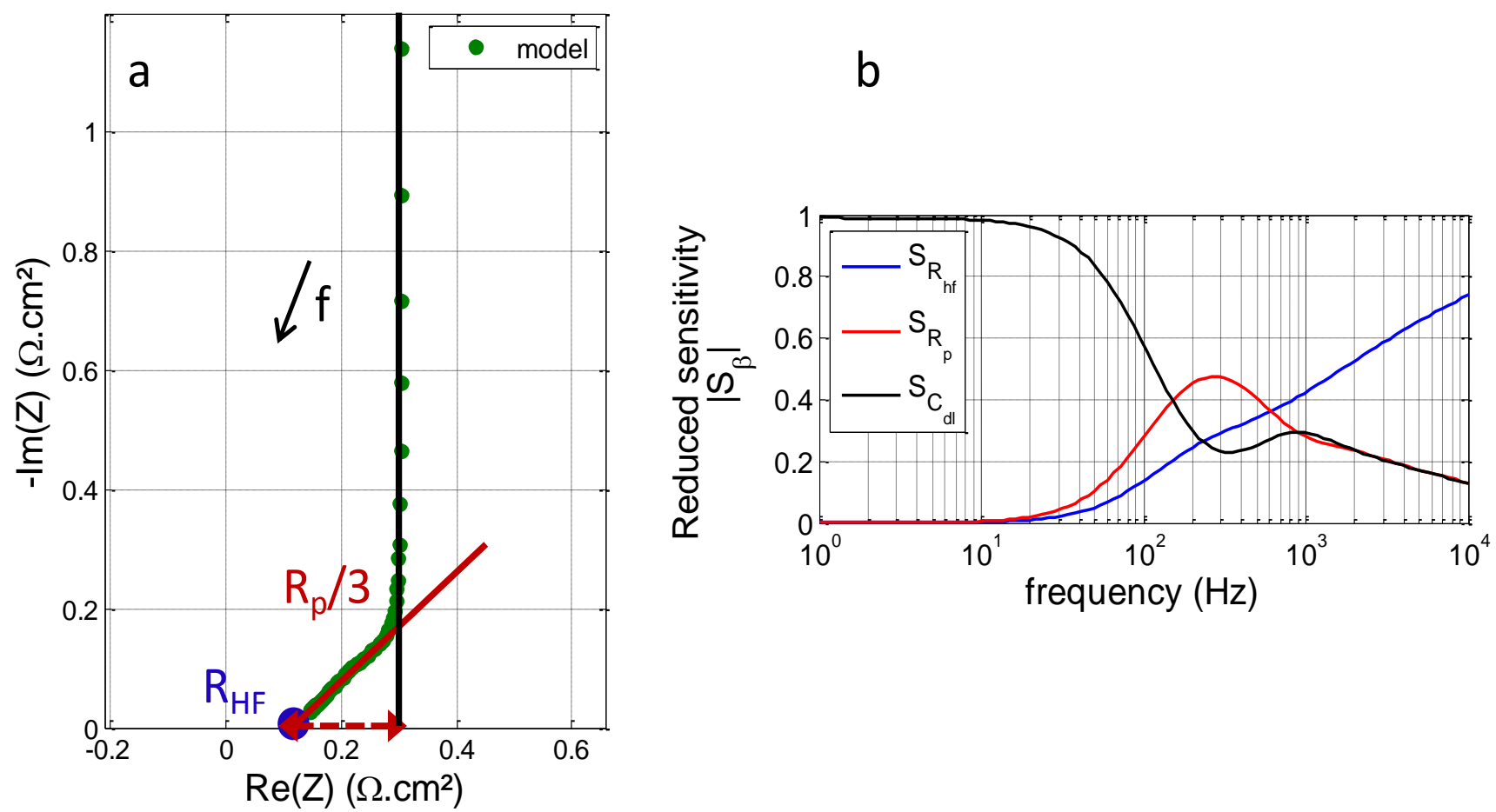

Figure 5: $\mathrm{H}_{2} / \mathrm{N}_{2}$ simulated spectrum (a) and reduced sensitivities of the system (b) computed for $R_{\mathrm{p}}=0.5 \Omega . \mathrm{cm}^{2}, \mathrm{C}_{\mathrm{dl}}=30 \mathrm{mF} / \mathrm{cm}^{2}$ and $\mathbf{R}_{\mathrm{HF}}=0.1 \Omega . \mathrm{cm}^{2}$

If two parameters or more are correlated, the condition number tends to infinity. Usually, inversion is considered as possible provided the condition number is below 50, depending on the signal to noise ratio. In our case, the condition number equals 5.4, which is much lower. Moreover, Figure 5 shows that the 3 sensitivities 
are above 0.05 in the frequency range selected. If one parameters had a sensitivity below 0.05 , its estimation would be very sensitive to the signal noise. At low frequencies (below $10 \mathrm{~Hz}$ ) the impedance is mainly sensitive to the double layer capacitance: the system behaves as a pure capacitance, depicting a vertical line in the EIS spectrum. At very high frequency (above $1 \mathrm{kHz}$ ), it is mainly sensitive to the high frequency resistance. At intermediate frequencies, the impedance is sensitive to the 3 parameters, but mainly to the protonic resistance, relatively to the module of the impedance.

\section{EXPERIMENTAL}

\subsection{Segmented cell and setup}

The measurements presented were performed using a linear segmented cell, specifically designed to resolve local impedance spectroscopy at high frequency. The bipolar plates had 5 straight parallel channels. The cathode plate consisted of 20 electrically insulated segments of $1 \times 1.5 \mathrm{~cm}^{2}$. The current was collected on each segment, and passed through a shunt resistor of $5 \mathrm{~m} \Omega$ to be measured. All shunt resistors were connected in parallel to the load. The anode was not segmented. $\mathrm{H}_{2}$ and air were fed in counter flow. The segments were numbered from 1 to 20. Segment 1 corresponds to air inlet and hydrogen outlet, segment 20 corresponds to air outlet and hydrogen inlet. Further information on the segmented fuel cell are available in [22]-[25]. The cell was operated at $80^{\circ} \mathrm{C}$ and 1.5 bar on both sides, except during the start-up procedure when the cell was operated at atmospheric pressure. The cell temperature was controlled using a cooling circuit and a thermostatic bath (Julabo®). The relative humidity of air was controlled with a calibrated water-bubbler. For hydrogen and nitrogen, the relative humidity was controlled by flow-meters, by mixingdry and $90 \%$ vapor saturated gas flows. Before each AST, the MEA were conditioned by repeating 50 times the following sequence: operation at $0.6 \mathrm{~V}$ for $45 \mathrm{~s}$, (b) open circuit for $30 \mathrm{~s}$, and (c) operation at $0.3 \mathrm{~V}$ for $60 \mathrm{~s}$. The electronic resistance $R_{\text {elec }}$ was measured with a high frequency Ohmmeter using the cell without MEA. It was estimated to be $38 \pm 3 \mathrm{~m} \Omega$.cm² (averaged on all segments).

\subsection{Potentio-static electrochemical impedance spectroscopy (EIS)}

The potentio-static spectra were acquired with the same setup. The DC potential was $0.5 \mathrm{~V}_{\mathrm{vs}}$ anode, and the dynamic perturbation was set to $25 \mathrm{mV}$, in the voltammetry region where no hydrogen sorption or desorption occured. Operation under nitrogen allowed a careful and homogeneous control of the relative humidity of supplied gases. Before each impedance measurement, the cell was kept under $\mathrm{H}_{2}$ for anodic compartment and under $\mathrm{N}_{2}$ for the cathode compartment at constant $\mathrm{RH}$ for one hour, which was sufficient to reach the water concentration equilibrium in Nafion ${ }^{\mathrm{TM}}$, for desorption or even for sorption [26]. The spectra were acquired for a range of frequency comprised between $10 \mathrm{kHz}$ and $1 \mathrm{~Hz}$. The experimental data were fitted to the model described in Eq. 7. The fit was done by minimizing the least square between data and model using the fminsearch function of Matlab based on the simplex method of Lagarias et al. [27].

\subsection{Materials}

State-of the art catalyst coated membrane MEA were used in this work. The global Pt loading of the MEA was ca. $0.5 \mathrm{mg} / \mathrm{cm}^{2}$, but the repartition between anode and cathode was not disclosed by the supplier. The membranes were Nafion ${ }^{\circledR}$ XL. The gas diffusion layers (GDL) were Sigracet ${ }^{\circledR} 24 B C$, and the gaskets were made of $210 \mu \mathrm{m}$ thick Teflon. The cell was assembled with a torque screwdriver to ensure reproducibility of the compression of GDL. The thickness of the membrane and cathode CL were measured using imageJ® software, taking the mean value of at least 15 measurements. 


\subsection{Sensitivity to relative humidity}

Impedance spectra were acquired at different RH to highlight the important sensitivity to humidity. This shows that a well controlled RH during the measurement is of prime importance for the reliability of the results (Figure 6). Just like the high frequency resistance $R_{H F}$, the catalyst layer protonic resistance $R_{p}$ decreased with RH. For $R_{H F}$ expression, the RH dependent term might be attributed to the resistance of the membrane, and the constant term might be attributed to the sum of the contact resistances between GDL/bipolar plate, the contact resistance GDL/electrode, and the electronic resistance of the acquisition system.

Contrary to $\mathrm{H}_{2} /$ air or $\mathrm{H}_{2} / \mathrm{O}_{2}$ EIS, $\mathrm{H}_{2} / \mathrm{N}_{2}$ EIS enables careful control of gas relative humidity within the cell by suppressing the protonic flux trough the membrane and thus the water electro-osmotic flux, as well as water gradients due to oxygen reduction at the cathode. There is also no heat production due to electrochemical reactions, which participates to the control of the local relative humidity.

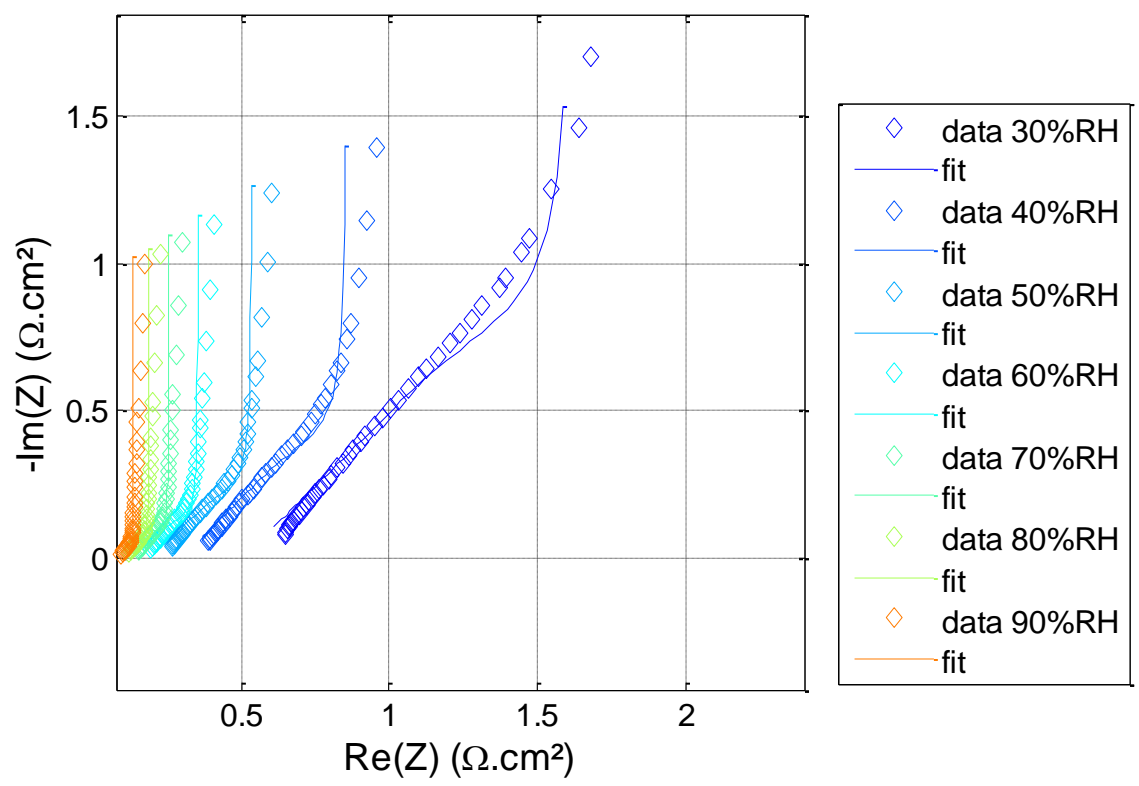

Figure 6: $\mathrm{H}_{2} / \mathbf{N}_{2}$ impedance spectra performed at different relative humidity on a fresh MEA

Assuming that the ionomer of the electrode and the ionomer of the membrane have the same resistivity, it is possible to establish a link between them using the volume fraction of ionomer in the electrode $\varepsilon_{i}$ and the tortuosity $\tau$ :

$\rho_{p}^{\text {eff }}=\frac{\rho_{i}}{\epsilon / \tau}$

Eq. 13

With $\rho_{p}{ }^{\text {eff }}$ the CL effective protonic resistivity and $\rho_{i}$ the bulk resistivity of the membrane. A first way to get the ionomer resistivity is to calculate it from the high frequency resistance $R_{H F}$ and the electronic resistance $R_{\text {elec }}$ measured on the cell mounted without MEA $\left(38 \pm 3 \mathrm{~m} \Omega . \mathrm{cm}^{2}\right)$. $\mathrm{R}_{\mathrm{m}}$ was measured at different $\mathrm{RH}$ from the impedance spectra of Figure 6 and fitted to an exponential function. The results of the fit yields: 
Thus, with $t_{m}$ and $t_{c}$ the thicknesses of the membrane and the cathode CL respectively, we get the expression of $\mathrm{R}_{\mathrm{p}}$ :

$R_{p}=\frac{t_{c}}{t_{m}} \frac{R_{m}}{\epsilon / \tau}$

Eq. 15

The $\varepsilon / \tau$ ratio was the only free parameter of the model. It was fitted from the experimental values of $R_{p}$ estimated by $\mathrm{H}_{2} / \mathrm{N}_{2}$ EIS. The results are plotted versus $\mathrm{RH}$ in Figure 7. The calculated effective protonic resistance of the CCL fits successfully the EIS measurement, and the best fit was found for $\varepsilon / \tau \approx 0.06$. The thicknesses of the membrane and cathode CL were measured from a SEM picture, being $31 \pm 1 \mu \mathrm{m}$ and $13 \pm 1 \mu \mathrm{m}$ respectively, giving $\mathrm{t}_{\mathrm{c}} / \mathrm{t}_{\mathrm{m}}=0.42 \pm 0.04$. The obtained value $\varepsilon / \tau=5.6 \pm 0.5 \%$, which corresponds to the volume fraction of ionomer within the CL was between $5 \%$ and $13 \%$ considering a tortuosity $\tau$ comprised between 1 and 2.2 according to [3], [4]. The second way to get the bulk ionic resistivity of the ionomer is to consider the values of membrane resistivity reported in the literature. The bulk resistivity measured by Maldonado et al. for Nafion 212 [28] and the corresponding effective protonic resistance using Eq. 15 were also plotted in Figure 7.

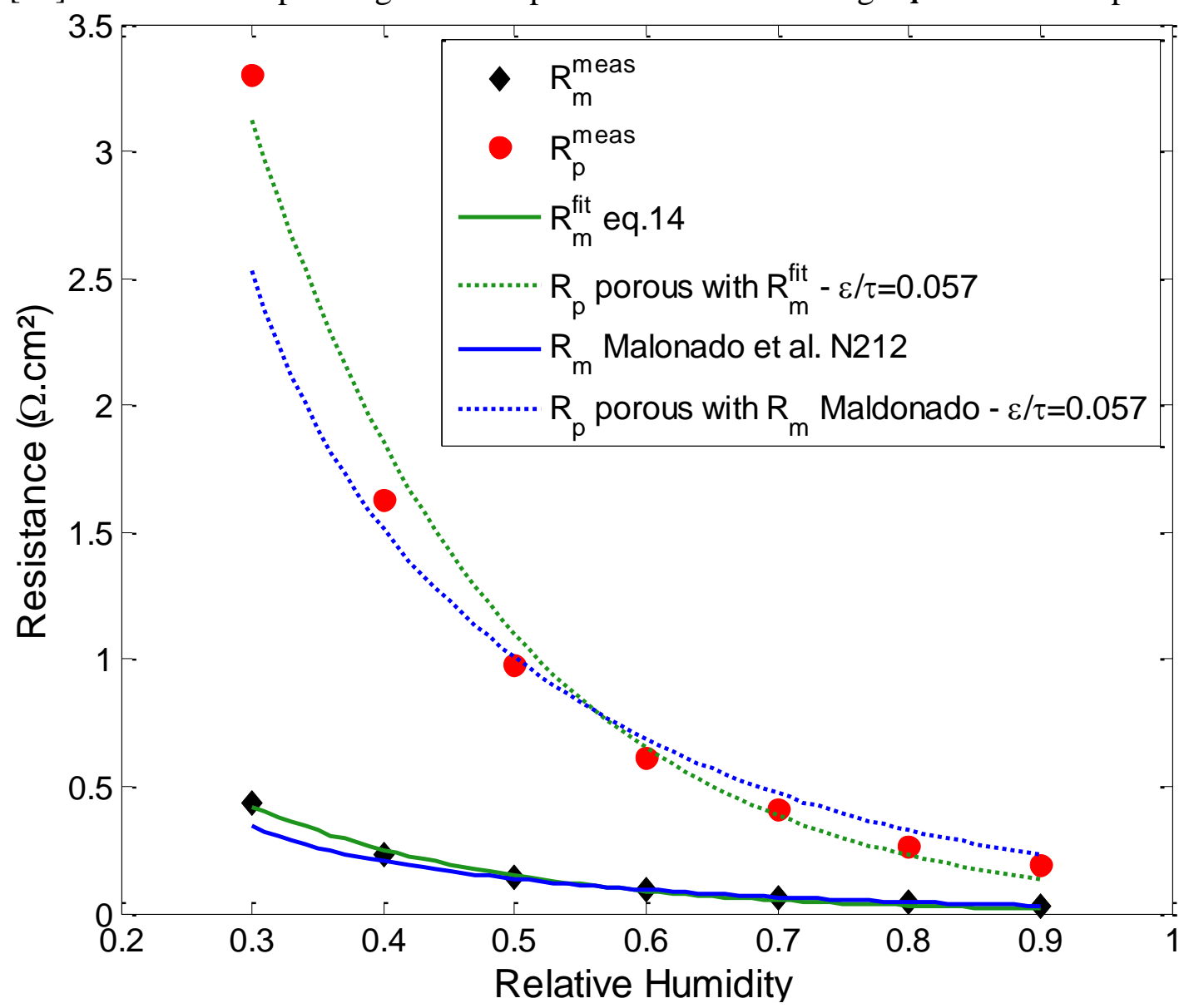

Figure 7: Parameters estimated from the impedance spectra of Figure $6: R_{p}$ (red points) and $\boldsymbol{R}_{H F}$ (blue squares). Green continuous line represents the empirical fit to the measured $R_{m}$ described in Eq. 14, green dashed line represents the calculation of $\boldsymbol{R}_{p}$ for a porous electrode model with a bulk resistivity equal to that measured for the membrane. Blue continuous line represents Maldonado expression for the membrane resistance, and blue dashed line represents $R_{p}$ for a porous electrode taking the bulk resistivity given by Maldonado et al. [28]. For $R_{p}$ calculations all values of $\varepsilon / \tau$ were fit at 0.06 . 


\section{ACCELERATED STRESS TESTS}

\subsection{Experimental}

It is not convenient to evaluate MEA durability using real fuel cell operating conditions because of time and resources available. Moreover, the degradations observed depend highly on the kind of solicitations to which the cell is submitted during the test. That is the reason why several standard accelerated stress test protocols (AST) have been developed to determine the durability of PEMFC components. The US department of Energy developed such tests designed to focus on specific degradations mechanisms [17]. In this work membrane degradation is studied using the DOE chemical membrane protocol (except for the pressure that was set to 1.5 bar). This test accelerates the membrane degradations by increasing the temperature and the partial pressure of oxygen and hydrogen in the absence of gas consumption. Carbon support corrosion was studied by performing the dedicated US DOE protocol. This test consists in a $1.2 \mathrm{~V}$ potentio-static hold regime, the cathode being fed with nitrogen. A start-up procedure summed up in Figure 8: Start-up procedure was also performed to study severe conditions that are close to those encountered in real operation.

Eventually, a reference test at idling conditions (constant current operation at $0.66 \mathrm{~A} / \mathrm{cm}^{2}$ ) was performed to check that the degradations observed during the AST were indeed induced by the nature of the test.

The accelerated stress test conditions are summed up in table I. During the constant current protocol, the OCV protocol, and the DOE carbon protocol, a full electrochemical characterization was performed each 24h. For these 3 tests the results led to homogeneous in space degradations. For the sake of simplicity these results are represented for the global cell.

For the start-up protocol, humid gases $(80 \% \mathrm{RH})$ were used to minimize the degradations due to $\mathrm{RH}$ cycling. Both anode purges with air and hydrogen were performed with $80 \%$ vapor saturated gases. In order to focus on start-up and to limit the degradations due to shut-down, the air purge flow rate at shut-down was set to ten times the $\mathrm{H}_{2}$ flow rate during start-up ( $20 \mathrm{slph}$ instead of $2 \mathrm{slph}$ ). Thus residence time of the hydrogen/air front was lowered during shut-down, leading to lower degradations [29], [30]. This test led to strongly heterogeneous degradations, and the results for this protocol are presented locally for each segment.

The characterization steps consisted in measuring polarization curves from 0 to $1.5 \mathrm{~A} / \mathrm{cm}^{2}$, local permeation current, local voltammetry between 0 and $1 \mathrm{~V}_{\text {/anode }}$ at $50 \mathrm{mV} / \mathrm{s}$, and local potentio-static EIS as specified in 3.2. Electrochemical surface area (ECSA) was measured between $0.1 \mathrm{Vvs}_{2}$ and $0.35 \mathrm{~V}_{\text {/anode. }}$. All characterizations were performed at $80^{\circ} \mathrm{C}, 50 \% \mathrm{RH}$, including during the membrane protocol. $\mathrm{H}_{2} / \mathrm{N}_{2}$ EIS and voltammetries were all performed at $50 \% \mathrm{RH}$.

TABLE I

ACCELERATED STRESS TESTS APPLIED IN THIS

\begin{tabular}{|c|c|c|c|c|}
\hline Protocol reference & Conditions & Anode & Cathode & T, P \\
\hline Constant current & $0.7 \mathrm{~A} / \mathrm{cm}^{2}, 168 \mathrm{~h}$ & $50 \% \mathrm{RH} \mathrm{H}_{2}$ & $50 \% \mathrm{RH}$ air & $80^{\circ} \mathrm{C}, 1.5 \mathrm{bar}$ \\
\hline DOE membrane & $\begin{array}{c}\text { Open Circuit Voltage, } \\
300 \mathrm{~h}\end{array}$ & $\begin{array}{c}34 \% \mathrm{RH} \mathrm{H}_{2} \\
(50 \% \text { during } \\
\text { characterization steps })\end{array}$ & $\begin{array}{c}34 \% \mathrm{RH} \text { air } \\
(50 \% \text { during characterization } \\
\text { steps })\end{array}$ & $\begin{array}{c}90^{\circ} \mathrm{C}, \\
\left(80^{\circ} \mathrm{C} \text { during }\right. \\
\text { characterization steps }) \\
1.5 \mathrm{bar}\end{array}$ \\
\hline DOE carbon & $1.2 \mathrm{~V}, 300 \mathrm{~h}$ & $50 \% \mathrm{RH} \mathrm{H}_{2}$ & $50 \% \mathrm{RH} \mathrm{N} 2$ & $80^{\circ} \mathrm{C}, 1.5 \mathrm{bar}$ \\
\hline $\begin{array}{c}\text { Start-up and Shut- } \\
\text { Down }\end{array}$ & $\mathrm{SU} \times 300$ & $\begin{array}{c}80 \% \mathrm{RH} \mathrm{H}_{2} \\
\text { Air purge } 80 \% \mathrm{RH} 20 \mathrm{slph}_{\mathrm{H}_{2} \text { purge } 2 \mathrm{slph}}\end{array}$ & $80 \% \mathrm{RH}$ air & $80^{\circ} \mathrm{C}, 1 \mathrm{bar}$ \\
\hline
\end{tabular}




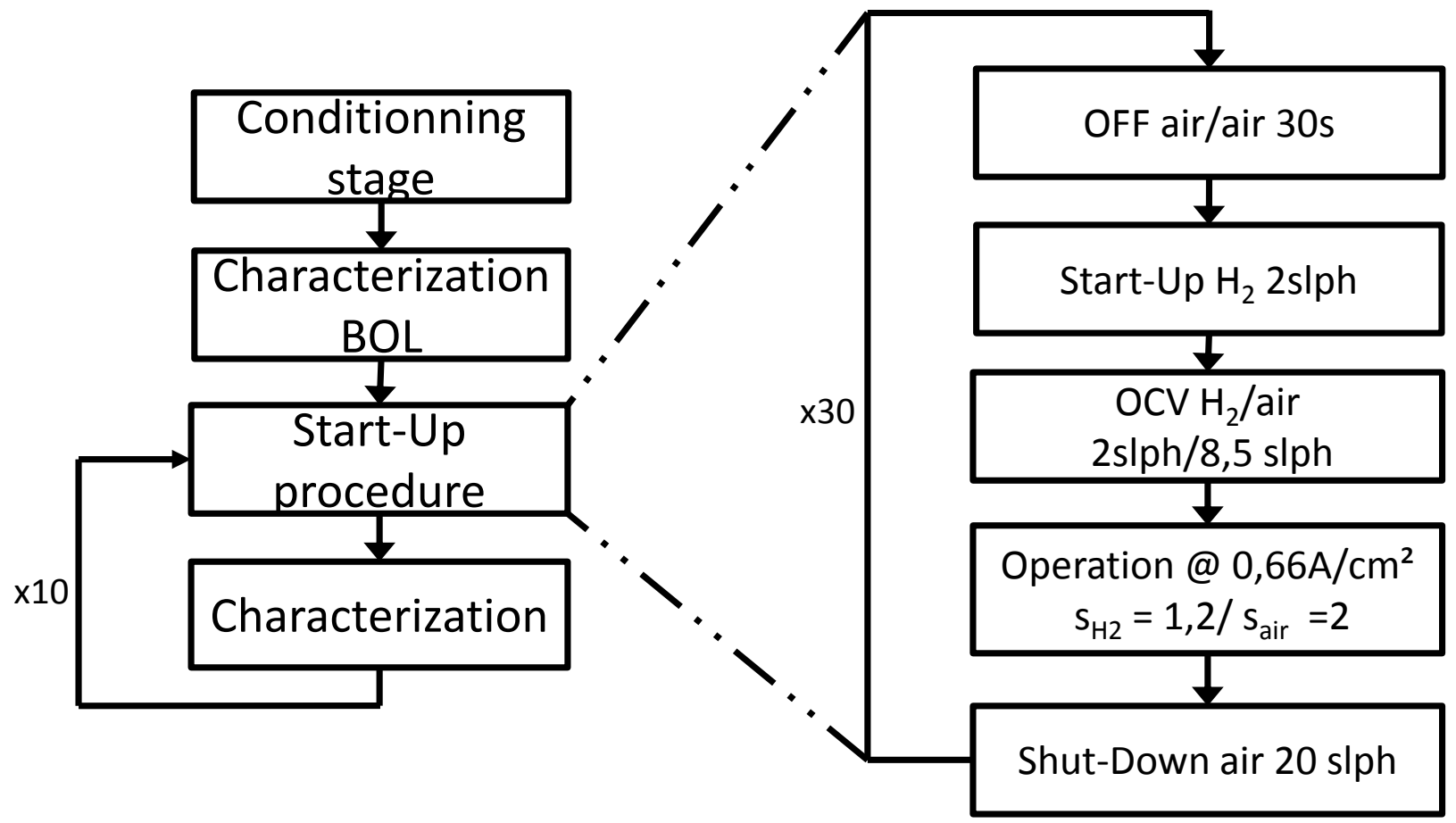

Figure 8: Start-up procedure

\subsection{Results of the degradations protocols}
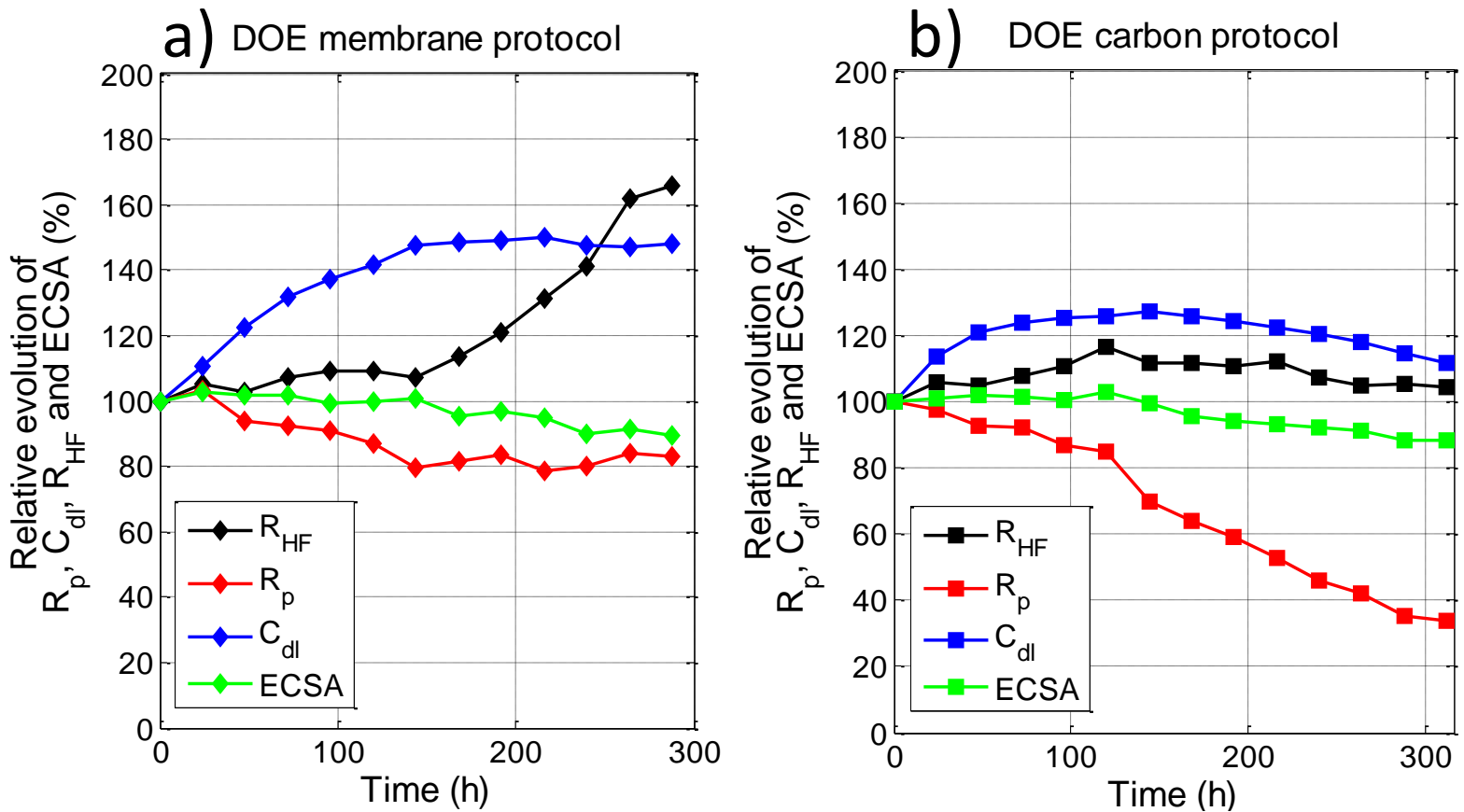

Figure 9: Evolution of the cathode protonic resistance $\mathbf{R}_{\mathrm{p}}$, of the high frequency resistance $\mathbf{R}_{\mathrm{HF}}$, of the double layer capacity $\mathrm{C}_{\mathrm{d}}$, and of the electrochemical surface area during the DOE membrane protocol (a) and DOE carbon protocol (b) presented in table I 
During the constant current protocol, no significant evolution of the parameters was noticed. $\mathrm{R}_{\mathrm{p}}$ decreased by $20 \%$ over $168 \mathrm{~h}$, and the evolutions of $\mathrm{C}_{\mathrm{dl}}, \mathrm{R}_{\mathrm{HF}}$, and the ECSA were lower than $15 \%$.

For the DOE membrane protocol, the double layer capacity increased by $50 \%$ after $150 \mathrm{~h}$, and then remained almost constant. The ECSA remained constant until 150h, and then decreased slightly to reach ca. $89 \%$ of the initial value after $300 \mathrm{~h} . \mathrm{R}_{\mathrm{p}}$ was $20 \%$ lower after $150 \mathrm{~h}$ and then remained constant. $\mathrm{R}_{\mathrm{HF}}$ increased by $70 \%$ along the test. This may be attributed to chemical membrane degradation by peroxy-radicals, leading at some places to a delamination at the reinforcement/cathode side membrane interface, or at the cathode CL/membrane interface. This interpretation is supported by SEM picture analysis of an aged membrane: there was a thinning of the zone of the membrane located between the reinforcement and the cathode CL (Figure 10). Nevertheless, no rise of $R_{p}$ was observed. The ionomer within the CCL seems to be preserved from chemical attack. The detailed mechanism for ionomer degradation is still to be discussed [31], [32]. Kundu et al [31] also observed a thinning of the membrane at the cathode side during an $\mathrm{OCV}$ test at $90^{\circ} \mathrm{C}$. The fluroride emission released at cathode exhaust was more than 2 times higher than at the anode exhaust, suggesting that the degradation mechanism occurred at the cathode side. This was supported by the presence of a Pt band close to the cathode CL. Ohma et. al [33] also performed an OCV test at $90^{\circ} \mathrm{C}, 30 \% \mathrm{RH}$, varying the gas composition (10\% diluted $\mathrm{H}_{2}$ or pure $\mathrm{H}_{2}$ at the anode, and oxygen or air at the cathode). They correlated the position of the Pt band observed by SEM with the calculated mixed potential for the different gas compositions used during the tests. They also observed a higher fluoride emission rate at the cathode when the Pt band was located closer to the cathode. Their study suggests that the attack of the ionomer occurs in the same region where the Pt band formation is favored. This could explain why during our OCV test which was performed with $\mathrm{H}_{2}$ /air, the membrane was attacked closer to the cathode side. Nevertheless, no Pt band was observed in our case.

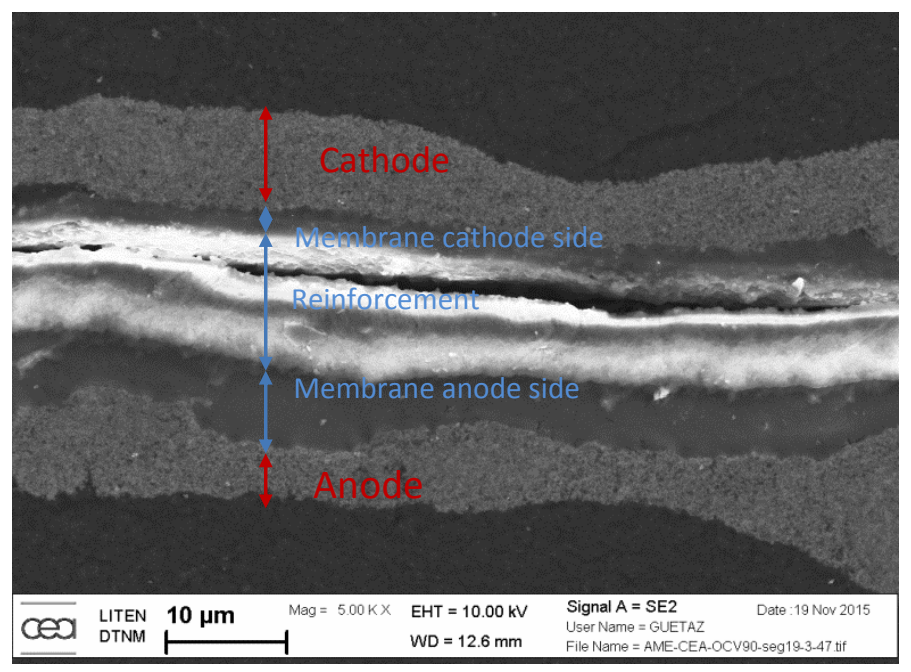

Figure 10: SEM picture of a MEA aged under OCV conditions (DOE membrane protocol described in table I)

During the DOE carbon protocol, almost no change in the ECSA was observed during the first 150h. In the meantime, there was a $30 \%$ increase of the double layer capacitance. After 150h, both the ECSA and the double layer capacitance decreased. Along the test, $R_{p}$ decreased significantly and continously to reach $c a$. $37 \%$ of its initial value.

To our point of view, three major phenomena could help interpreting the $C_{d l}$ evolution during the AST: 
- First of all, one has to keep in mind that the double layer capacitance measured by $\mathrm{H}_{2} / \mathrm{N}_{2}$ impedance spectroscopy at $0.5 \mathrm{~V}$ is strongly linked to the ECSA: Young et al. [34] showed the strong correlation between ECSA and the double layer capacitance.

- Another phenomenon that has to be taken into account is the partial oxidation of carbon surface. It is a partially reversible phenomenon concerning mostly the carbon groups located on the external foil of the carbon particles, creating oxygen functionalities on the surface, e.g. quinone or hydroquinone groups [35] [36]. An oxidized surface of carbon would show an increased double layer capacitance due to the pseudo-capacitive behavior of these surface groups during the EIS measurement [37]. These groups are also more hydrophilic and could retain a water film, increasing thus the ionic phase/carbon phase interface.

- A third phenomenon concerns the oxidation of carbon supports into $\mathrm{CO}_{2}$ that causes a compaction of the electrode. If the CCL ionomer remains unattacked, a severe loss of carbon leads to (i) a loss of connectivity of the carbon and platinum particles and (ii) a loss of the carbon/ionomer interface.

To check the reversibility of the $C_{d l}$ increase, the MEA aged under OCV conditions (Figure 9) was reconditioned for 2 hours following the sequence described above in the experimental section. This re-conditioning step led to a decrease of $C_{d l}$ from $42 \mathrm{mF} / \mathrm{cm}^{2}$ to $36 \mathrm{mF} / \mathrm{cm}^{2}$ i.e. a decrease from $c a .147 \%$ to $c a .125 \%$ of the initial $C_{d l}$ value of the fresh MEA. This observation partially confirms the scenario of carbon reversible oxidation during OCV protocols. Oxidation of surface carbons may also explain the $C_{d l}$ increase over the first $150 \mathrm{~h}$ of the DOE carbon protocol. The increase in $\mathrm{C}_{\mathrm{dl}}$ was confirmed by measuring the double layer capacitance on the cyclic voltammetries between $0.45 \mathrm{~V}$ and $0.55 \mathrm{~V}$, which is usually attributed to the quinone/hydroquinone region [35] [36]. The following decrease in $C_{d l}$ over the last $150 \mathrm{~h}$ can be attributed to the structure compaction of the CCL. Carbon oxidation into $\mathrm{CO}_{2}$ also results in an electronic connectivity loss that would also explain the simultaneous ECSA decrease.

The drop of $R_{p}$ during the DOE carbon protocol can be interpreted in terms of:

- CCL compaction. Since $R_{p}=\rho_{p} t_{c}$, a decrease in $t_{c}$ leads to a decrease in $R_{p}$. Not only does the thickness decreases, but the electrode microstrucure collapses. Carbon corrosion leads to a thin layer with high volume fraction of ionomer and platinum. For an unchanged volume of ionomer, the volume fraction $\epsilon=\frac{V_{i o n}}{t_{c} S_{C C L}}$ would increase while $t_{c}$ decreases, leading to an additional drop in the measured value of $R_{p}$. Young et al. also measured a similar decrease in $R_{p}$ during repeated cycling between $0.15 \mathrm{~V}$ and $1.5 \mathrm{~V}$ and they observed by a postmortem analysis a thinning of the CCL [38].

- Carbon surface properties. The drop of $R_{p}$ can also result from a hydrophobicity loss of the carbon following the formation of hydrophilic surface functionalities. This may lead to small distance enhancement of ionic conduction via a water film. Kangasniemi et al.[35] characterized TFE-Vulcan and observed a hydrophobicity loss measured by contact angles after a $1.2 \mathrm{~V}$ hold at $65^{\circ} \mathrm{C}$.

High potential excursions during start-up events -up to $1.5 \mathrm{~V}_{\mathrm{vs}} \mathrm{RHE}$ - have been reported in the literature, resulting in a thinning of the electrode and $\mathrm{CO}_{2}$ emissions in the cathode exhaust [25], [30], [39]. The authors have shown that very local degradations originate from start-up events. During this AST, shut-down were performed at a high air flow rate to reduce its impact on the degradations and observe mainly the damages caused by startup events. Start-up events caused a severe damage in the cathode side located close to the hydrogen outlet. Our results show an important decrease in both $R_{p}$ and $C_{d l}$ in this preferential zone which was exposed the longest to 
high potentials. This supports the interpretation of the loss of $R_{p}$ and $C_{d l}$ due to the electrode structure compaction.
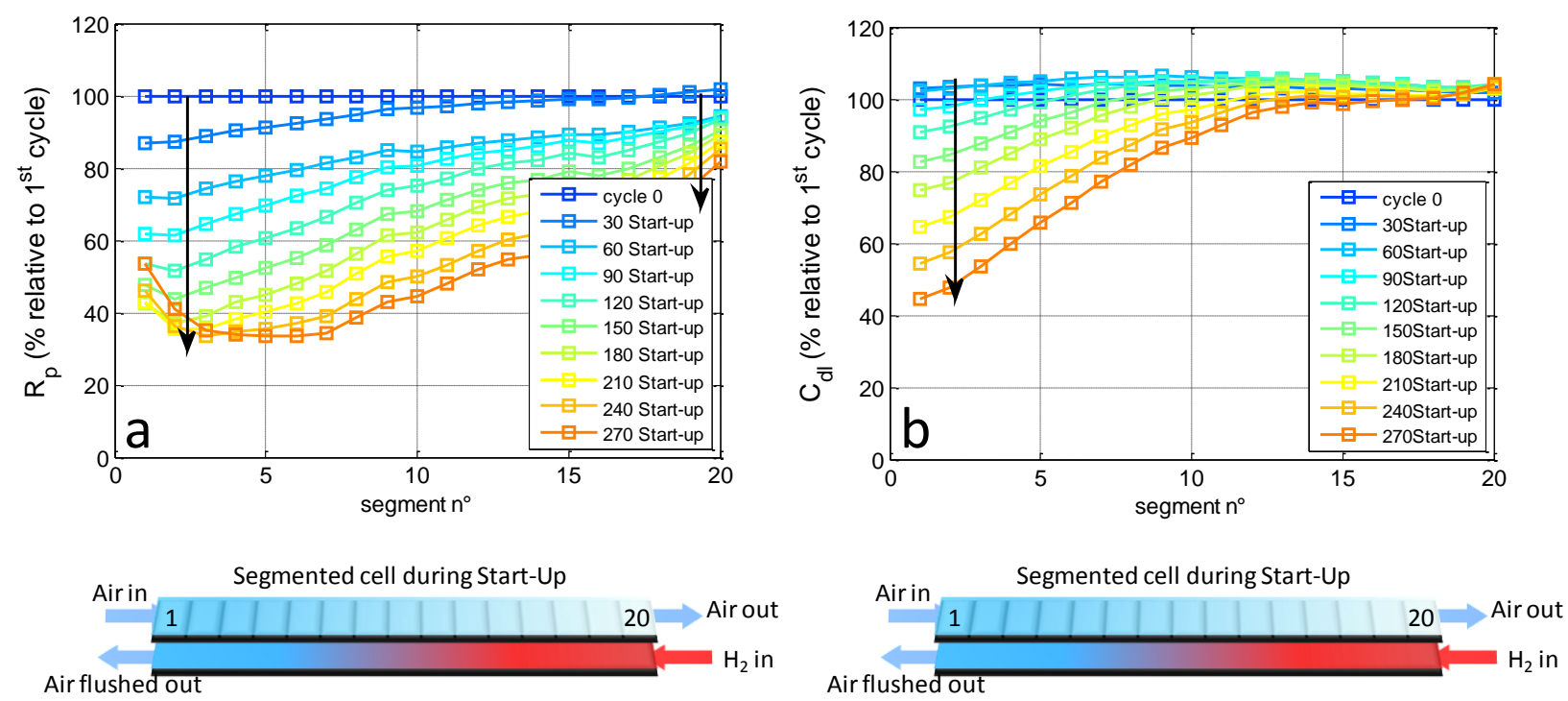

Figure 11: Evolution of the profile of $R_{p}(a)$ and $C_{d l}(b)$ of an MEA submitted to a start-up protocol. The profiles are presented along the segmented fuel cell

\section{CONCLUSION}

$\mathrm{H}_{2} / \mathrm{N}_{2}$ potentio-static EIS can be simply implemented during MEA characterization. It provides complementary information to those of conventional electrochemical tests, helping the interpretation of the electrode and membrane evolution during AST. The double layer capacitance, the protonic resistance of the electrode, and the high frequency resistance can be estimated from the spectra with no risk of correlation. The main assumptions to estimate these parameters are the homogeneous structure of the MEA in terms of thickness, and in terms of in-plane and through-plane distributions of the ionomer of the CCL. These assumptions can be checked by looking the shape of the spectra on fresh MEA: the slope of the high frequency region must be equal to $45^{\circ}$ and there must be a single discontinuity between the vertical low frequency line and the $45^{\circ}$ high frequency slope. The protonic resistance of the CCL and that of the membrane show identical behavior $v s$. gas relative humidity. Therefore, a porous model of electrode is adapted to describe the effective protonic resistivity $\rho_{p} .3$ accelerated stress tests were performed. The first one consisted in an OCV test leading to an increase of the membrane resistance and a meantime thinning of the membrane close to the cathode CL. Nonetheless, no degradation of the CCL ionomer was evidenced during this test. The second one consisted in a $1.2 \mathrm{~V}$ hold potential test. A compaction of the electrode due to carbon corrosion was assumed to cause the observed drop in $R_{p}$ and $C_{d l}$. The last accelerated stress test consisted in the repetition of start-up events, yielding to local damage of the cathode catalyst layer close to the anode outlet. It is believed that the exposition to high potentials causes effects similar as the $1.2 \mathrm{~V}$ protocol.

\section{REFERENCES}

[1] T. E. Springer, "Modeling and Experimental Diagnostics in Polymer Electrolyte Fuel Cells," J. Electrochem. Soc., vol. 140, no. 12, p. 3513, 1993. 
[2] K. C. Neyerlin, W. Gu, J. Jorne, A. Clark, and H. A. Gasteiger, "Cathode Catalyst Utilization for the ORR in a PEMFC," J. Electrochem. Soc., vol. 154, no. 2, p. B279, 2007.

[3] C. Boyer, S. Gamburzev, O. Velev, S. Srinivasan, and A. Appleby, "Measurements of proton conductivity in the active layer of PEM fuel cell gas diffusion electrodes," ELECTROCHIMICA ACTA, vol. 43, no. 24, pp. 3703-3709, 1998.

[4] H. Iden, A. Ohma, and K. Shinohara, "Analysis of Proton Transport in Pseudo Catalyst Layers," J. Electrochem. Soc., vol. 156, no. 9, pp. B1078-B1084, 2009.

[5] Z. Siroma, J. Hagiwara, K. Yasuda, M. Inaba, and A. Tasaka, "Simultaneous measurement of the effective ionic conductivity and effective electronic conductivity in a porous electrode film impregnated with electrolyte," J. Electroanal. Chem., vol. 648, no. 2, pp. 92-97, Oct. 2010.

[6] T. E. Springer, "Characterization of Polymer Electrolyte Fuel Cells Using AC Impedance Spectroscopy," J. Electrochem. Soc., vol. 143 , no. 2, p. 587, 1996.

[7] M. Eikerling and A. A. Kornyshev, "Electrochemical impedance of the cathode catalyst layer in polymer electrolyte fuel cells," $J$. Electroanal. Chem., vol. 475, no. 2, pp. 107-123, 1999.

[8] R. Makharia, M. F. Mathias, and D. R. Baker, "Measurement of Catalyst Layer Electrolyte Resistance in PEFCs Using Electrochemical Impedance Spectroscopy,” J. Electrochem. Soc., vol. 152, no. 5, p. A970, 2005.

[9] A. A. Kulikovsky, "A physical model for catalyst layer impedance," J. Electroanal. Chem., vol. 669, pp. 28-34, Mar. 2012.

[10] T. V. Reshetenko, G. Bender, K. Bethune, and R. Rocheleau, "Systematic study of back pressure and anode stoichiometry effects on spatial PEMFC performance distribution," Electrochimica Acta, vol. 56, no. 24, pp. 8700-8710, Oct. 2011.

[11] A. A. Kulikovsky and M. Eikerling, "Analytical solutions for impedance of the cathode catalyst layer in PEM fuel cell: Layer parameters from impedance spectrum without fitting," J. Electroanal. Chem., vol. 691, pp. 13-17, Feb. 2013.

[12] O. E. Barcia, E. D'Elia, I. Frateur, and O. . Mattos, "Application of the impedance model of de Levie for the characterization of porous electrodes," Electrochimica Acta, vol. 47, pp. 2109-2116, Jun. 2002.

[13] G. Li and P. G. Pickup, "Ionic Conductivity of PEMFC Electrodes," J. Electrochem. Soc., vol. 150, no. 11, p. C745, 2003.

[14] X. Ren and P. G. Pickup, "Simulation and analysis of the impedance behaviour of electroactive layers with non-uniform conductivity and capacitance profiles," Electrochimica Acta, vol. 46, no. 26, pp. 4177-4183, 2001.

[15] D. Malevich, B. R. Jayasankar, E. Halliop, J. G. Pharoah, B. A. Peppley, and K. Karan, "On the Determination of PEM Fuel Cell Catalyst Layer Resistance from Impedance Measurement in H2/N2 Cells," J. Electrochem. Soc., vol. 159, no. 12, pp. F888-F895, Jan. 2012.

[16] J. W. Lim, Y.-H. Cho, M. Ahn, D. Y. Chung, Y.-H. Cho, N. Jung, Y. S. Kang, O.-H. Kim, M. J. Lee, M. Kim, and Y.-E. Sung, "Ionic Resistance of a Cathode Catalyst Layer with Various Thicknesses by Electrochemical Impedance Spectroscopy for PEMFC," J. Electrochem. Soc., vol. 159, no. 4, p. B378, 2012.

[17] R. Borup, J. Meyers, B. Pivovar, Y. S. Kim, R. Mukundan, N. Garland, D. Myers, M. Wilson, F. Garzon, D. Wood, P. Zelenay, K. More, K. Stroh, T. Zawodzinski, J. Boncella, J. E. McGrath, M. Inaba, K. Miyatake, M. Hori, K. Ota, Z. Ogumi, S. Miyata, A. Nishikata, Z. Siroma, Y. Uchimoto, K. Yasuda, K. Kimijima, and N. Iwashita, "Scientific Aspects of Polymer Electrolyte Fuel Cell Durability and Degradation," Chem. Rev., vol. 107, no. 10, pp. 3904-3951, Oct. 2007.

[18] X. Yuan, H. Wang, J. Colinsun, and J. Zhang, "AC impedance technique in PEM fuel cell diagnosis—A review," Int. J. Hydrog. Energy, vol. 32, no. 17, pp. 4365-4380, Dec. 2007.

[19] J. Mainka, G. Maranzana, J. Dillet, S. Didierjean, and O. Lottin, "On the estimation of high frequency parameters of Proton Exchange Membrane Fuel Cells via Electrochemical Impedance Spectroscopy,” J. Power Sources, vol. 253, no. 0, pp. 381-391, May 2014.

[20] M. A. Rubio, A. Urquia, R. Kuhn, and S. Dormido, "Electrochemical parameter estimation in operating proton exchange membrane fuel cells," J. Power Sources, vol. 183, no. 1, pp. 118-125, Aug. 2008.

[21] D. Gerteisen, "Impact of Inhomogeneous Catalyst Layer Properties on Impedance Spectra of Polymer Electrolyte Membrane Fuel Cells," J. Electrochem. Soc., vol. 162, no. 14, pp. F1431-F1438, 2015.

[22] S. Abbou, J. Dillet, D. Spernjak, R. Mukundan, J. D. Fairweather, R. L. Borup, G. Maranzana, S. Didierjean, and O. Lottin, "Time Evolution of Local Potentials during PEM Fuel Cell Operation with Dead-Ended Anode," ECS Trans., vol. 58, no. 1, pp. 1631-1642, Oct. 2013.

[23] S. Abbou, J. Dillet, D. Spernjak, R. Mukundan, R. L. Borup, G. Maranzana, and O. Lottin, "High Potential Excursions during PEM Fuel Cell Operation with Dead-Ended Anode,” J. Electrochem. Soc., vol. 162, no. 10, pp. F1212-F1220, 2015.

[24] J. Dillet, D. Spernjak, A. Lamibrac, G. Maranzana, R. Mukundan, J. Fairweather, S. Didierjean, R. L. Borup, and O. Lottin, "Impact of flow rates and electrode specifications on degradations during repeated startups and shutdowns in polymer-electrolyte membrane fuel cells," J. Power Sources, vol. 250, pp. 68-79, Mar. 2014.

[25] J. Dillet, A. Lamibrac, G. Maranzana, J. Durst, D. Spernjak, J. D. Fairweather, R. Mukundan, R. L. Borup, S. Didierjean, and O. Lottin, "Internal Currents, CO2 Emissions and Decrease of the Pt Electrochemical Surface Area during Fuel Cell Start-Up and Shut-Down," ECS Trans., vol. 50, no. 2, pp. 701-710, Mar. 2013. 
[26] S. Didierjean, J. C. Perrin, F. Xu, G. Maranzana, M. Klein, J. Mainka, and O. Lottin, "Theoretical evidence of the difference in kinetics of water sorption and desorption in Nafion ${ }^{\circledR}$ membrane and experimental validation," J. Power Sources, vol. 300, pp. 50-56, Dec. 2015.

[27] J. C. Lagarias, J. A. Reeds, M. H. Wright, and P. E. Wright, "Convergence properties of the Nelder-Mead simplex method in low dimensions," SIAM J. Optim., vol. 9, no. 1, pp. 112-147, 1998.

[28] L. Maldonado, J.-C. Perrin, J. Dillet, and O. Lottin, "Characterization of polymer electrolyte Nafion membranes: Influence of temperature, heat treatment and drying protocol on sorption and transport properties," J. Membr. Sci., vol. 389, pp. 43-56, Feb. 2012.

[29] A. Lamibrac, G. Maranzana, O. Lottin, J. Dillet, J. Mainka, S. Didierjean, A. Thomas, and C. Moyne, "Experimental characterization of internal currents during the start-up of a proton exchange membrane fuel cell," J. Power Sources, vol. 196, no. 22, pp. 9451-9458, Nov. 2011.

[30] J. Dillet, D. Spernjak, A. Lamibrac, G. Maranzana, R. Mukundan, J. Fairweather, S. Didierjean, R. L. Borup, and O. Lottin, "Impact of flow rates and electrode specifications on degradations during repeated startups and shutdowns in polymer-electrolyte membrane fuel cells," J. Power Sources, vol. 250, no. 0, pp. 68-79, Mar. 2014.

[31] S. Kundu, M. W. Fowler, L. C. Simon, R. Abouatallah, and N. Beydokhti, "Degradation analysis and modeling of reinforced catalyst coated membranes operated under OCV conditions," J. Power Sources, vol. 183, no. 2, pp. 619-628, Sep. 2008.

[32] T. H. Yu, Y. Sha, W.-G. Liu, B. V. Merinov, P. Shirvanian, and W. A. Goddard, "Mechanism for Degradation of Nafion in PEM Fuel Cells from Quantum Mechanics Calculations,” J. Am. Chem. Soc., vol. 133, no. 49, pp. 19857-19863, Dec. 2011.

[33] A. Ohma, S. Suga, S. Yamamoto, and K. Shinohara, "Membrane Degradation Behavior during Open-Circuit Voltage Hold Test," J. Electrochem. Soc., vol. 154, no. 8, p. B757, 2007.

[34] A. P. Young, J. Stumper, S. Knights, and E. Gyenge, "Ionomer Degradation in Polymer Electrolyte Membrane Fuel Cells," J. Electrochem. Soc., vol. 157, no. 3, p. B425, 2010.

[35] K. H. Kangasniemi, D. A. Condit, and T. D. Jarvi, "Characterization of Vulcan Electrochemically Oxidized under Simulated PEM Fuel Cell Conditions," J. Electrochem. Soc., vol. 151, no. 4, p. E125, 2004.

[36] S. C. Ball, S. L. Hudson, D. Thompsett, and B. Theobald, "An investigation into factors affecting the stability of carbons and carbon supported platinum and platinum/cobalt alloy catalysts during $1.2 \mathrm{~V}$ potentiostatic hold regimes at a range of temperatures," J. Power Sources, vol. 171, no. 1, pp. 18-25, Sep. 2007.

[37] O. Reid, F. S. Saleh, and E. B. Easton, "Determining electrochemically active surface area in PEM fuel cell electrodes with electrochemical impedance spectroscopy and its application to catalyst durability," Electrochimica Acta, vol. 114, pp. 278-284, Dec. 2013.

[38] A. P. Young, J. Stumper, and E. Gyenge, "Characterizing the Structural Degradation in a PEMFC Cathode Catalyst Layer: Carbon Corrosion,” J. Electrochem. Soc., vol. 156, no. 8, p. B913, 2009.

[39] J. Durst, A. Lamibrac, F. Charlot, J. Dillet, L. F. Castanheira, G. Maranzana, L. Dubau, F. Maillard, M. Chatenet, and O. Lottin, "Degradation heterogeneities induced by repetitive start/stop events in proton exchange membrane fuel cell: Inlet vs. outlet and channel vs. land," Appl. Catal. B Environ., vol. 138-139, no. 0, pp. 416-426, Jul. 2013. 